\title{
President's Message
}

The Asian Pacific Association for Laser Medicine \& Surgery (APALMS) was officially founded in Tokyo in 1985, and the first scientific meeting was held in Tokyo (President: Kazuhiko Atsumi) that year. The purpose of the APLMS is not only to deliver academic information but also present technological, industrial and social innovations.

The 13th meeting will be held in Japan after an interval of 25 years. It is a great pleasure for me to announce that the 13th Congress of the APALMS will be held in the beautiful Japanese Alps from October 8th to 9th 2010, in Suwa City, Nagano Prefecture, a recent host of the Winter Olympics. Suwa City is famous as a summer resort and is situated on a beautiful plateau, with a lake and fantastic hot springs.

At the recent Laser Tokyo 2009 meeting held in November/December of last year, the inaugural didactic,

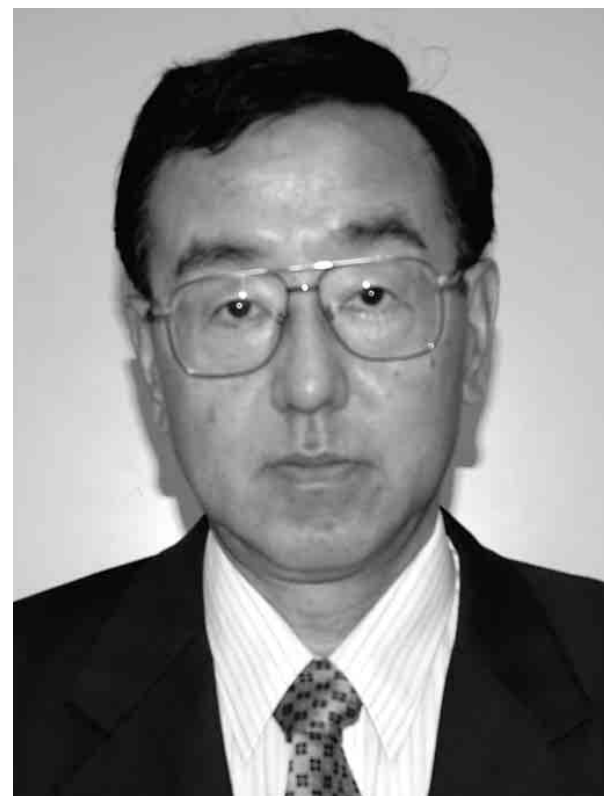
hands-on training and examination sessions of the International Medical Laser Specialist (IMeLaS) certification initiative were successfully held. IMeLaS certification is a new joint initiative run under the auspices of the International Society for Laser Medicine and Surgery (ISLSM), the World Federation of Societies for Laser Medicine and Surgery (WFSLMS) and the International Academy Laser Medicine and Surgery (IALMS) to provide internationally-recognized certification for all specialists using the laser in medicine and surgery. Forty-six successful candidates (2 at I-IMeLaS, 1 at A-IMeLaS, 4 at B-IMeLaS, 8 at CIMeLaS, 9 at P-IMeLaS and 22 at Hon-IMeLaS) have already been certified, and I am proud to announce that the second IMeLaS initiative will take place on October $6^{\text {th }}$ and $7^{\text {th }}$, before the 13th APALMS. There will be a limited number of places, so speedy application is required to secure a place on this valuable course. Full information on the IMeLaS course, including an application form, can be found elsewhere on this website ..... please follow the IMeLaS link!

October is a marvellous season in Nagano, with the wonderful colors of autumn reflected in the mirror-still lake on the shores of which the congress hotel is located. I heartily encourage you to attend this meeting to fill your mind with the intellectual fruits of the meeting, your stomachs with the tasty local delicacies and rice wines, and your eyes with the autumnal beauty of Suwa City in October. You will be made most welcome!

\section{Yoshimi Asagai, MD}

President of the 13th Congress of APALMS

Chairman of the Board, Shinano Handicapped Children's Hospital Visiting Professor of Orthopedic Surgery, Tokyo Medical University 